\title{
VIOLENCIAS INSTITUCIONALIZADAS. EL DISCURSO JUDICIAL SOBRE LAS MUJERES
}

María Angélica Peñas Defago ${ }^{1}$

Centro de Investigaciones Jurídicas y Sociales

\section{Resumen}

En Argentina, a pesar de numerosas reformas legales, el campo judicial continúa reproduciendo un sistema de ordenación heteropatriarcal que perpetua la violencia contra las mujeres. A través de este trabajo intentaremos identificar cómo operan en las Cortes argentinas una serie de discursos desde donde se consolida la violencia de género bajo giros discursivos propios de este campo como la abstracción y la universalidad.

Palabras-claves: violencia contra las mujeres; discurso judicial; cortes de justicia; Argentina.

\section{Résumé}

Violence institutionnalisée: Le discours judiciaire sur les femmes

En Argentine, malgré de nombreuses réformes légales, le milieu judiciaire reproduit toujours un système d'ordonnance hétéropatriarcale qui perpétue les violences contre les femmes. A travers ce travail, nous essayerons d'identifier la manière dont opèrent dans les cours de justice argentines une série de discours depuis lesquels la violence de genre se consolide grâce à des tournures discursives propres de ce champ, comme l'abstraction et l'universalité.

Mots-clés: violences contre les femmes; discours judiciaire; les cours de justice; Argentine.

\section{Abstract}

Institutionalized violence: The judicial discourse about women

In Argentina, despite numerous legislative initiatives, the judicial arena continues reproducing heteropatriarchal models of social order. Through this work we will try to identify how a series of discourses that perpetuate and consolidate gender violence in the field of justice in Argentina, under multiple discursive turns as abstraction and the universality of law.

Keywords: violence against women; judicial discourse-courts of justice; Argentina.

\section{Introducción}

La progresiva y explicita consagración legal del derecho de las mujeres ${ }^{2}$ a una vida libre de violencias ha ingresado en las agendas públicas latinoamerica-

Centro de Investigaciones Jurídicas y Sociales, UNC. angelicapdefago@hotmail.com

Compartimos aquí las críticas realizadas por diversos/as exponentes en torno a concebir a las mujeres no como un sujeto único y universal. Los intentos de homologación de las diferencias que entrañan las sujetas «mujeres» deviene en una práctica común en los discursos jurídicos. 
nas en las últimas décadas de la mano de los movimientos de mujeres y feministas. Entre otros aspectos, estos movimientos denuncian/ban la estrecha conexión de la violencia de género con los altos índices de inequidad y pobreza que existen en América Latina (Mones y Guzmán, 1998). En paralelo, la complejidad que plantean los escenarios concretos de implementación de las leyes logradas, nos señalan una vez más cómo si bien el derecho puede ser una de las vías para erradicar y desmantelar las diferentes estructuras que perpetúan la violencia de género, no obstante su interpretación, en múltiples ocasiones, continúa siendo llevada adelante por una serie de personas e instituciones que operan bajo paradigmas patriarcales de ordenación social (Jaramillo, 2000). Es que si bien el derecho, en tanto discurso social históricamente situado, puede constituirse en una herramienta capaz de contribuir a la modificación de estereotipos desde los cuales se legitima la discriminación y violencia contra mujeres y niñas, en muchas ocasiones las leyes tendientes a erradicar las violencias de género han tendido a fragmentar las vivencias y realidades múltiples donde se insertan las experiencias vitales de las personas ${ }^{3}$. Uno de los espacios donde más fuertemente se evidencia esta fragmentación es en las Cortes de Justicia.

Analizar el discurso judicial/legal en materia de violencia contra mujeres y niñas implica al menos dos ejercicios de reflexión de candente relevancia política y académica. Uno de los aspectos claves de este análisis nos remite a observar cómo en la práctica opera un continuo proceso de ampliación del lenguaje de derechos promovido por los movimientos de mujeres, feministas y de derechos humanos, en tanto vía posible de erradicación de las violencias contra las mujeres y otros sectores sexualmente disidentes, procesos en su mayoría, acompañados por movilizaciones de cariz regional e internacional (Chiarotti, 2006; Pecheny y De La Deheza, 2009; Chinkin, 2012).

Por otro lado, y sin desconocer la trascendencia de estos debates, deviene necesario profundizar en el análisis de cómo las Cortes en temas de derechos de las mujeres y sectores disidentes de un hegemónico ordenamiento social y cultural, pueden perpetuar y reforzar una serie de estereotipos de género. El análisis de la jurisprudencia devine en una arena clave desde donde poder indagar respecto de cuáles son los presupuestos y/o marcos de sentidos en los que continúan concibiéndose los derechos y sus correlativas/os sujetas/os de derechos ante con-

3 Una iniciativa con intento superador en este sentido, es la ley 26.485 de Protección Integral para Prevenir, Sancionar y Erradicar la Violencia contra las Mujeres en los Ámbitos en que Desarrollen sus Relaciones Interpersonales de 2009. A nivel de los poderes judiciales las principales iniciativas en Argentina tendientes a incorporar perspectiva de género han sido impulsadas centralmente por la Corte Suprema de Justicia Nacional quien en 2009 crea la Oficina de la Mujer y un año antes, en 2008, había creado la Oficina de Violencia Domestica (OVD) cuyo objetivo es facilitar el acceso a la justicia de personas afectadas por hechos de violencia doméstica, recibiendo denuncias y consultas. Según reportan diferentes informes elaborados por las OVD alrededor de un $90 \%$ de las consultas como de denuncias por violencia domestica son realizadas por mujeres y niñas. 
textos de violencia de género. El estudio de este ámbito estatal, nos permitirá acercarnos y cuestionarnos, respecto de cómo opera el discurso jurídico y las prácticas judiciales en tanto constructoras y/o reproductoras de órdenes sociales jerárquicos, todo ello en la mayoría de los casos, articulado bajo el velo de la abstracción, universalidad y neutralidad de las normas jurídicas. Nuestra propuesta intenta abordar la indagación en torno a los procesos de significación y construcción «de la/s mujer/es» en los discursos judiciales, en tanto ámbitos móviles de disputas y tensiones por el saber y poder.

A través de este trabajo pretendemos identificar una serie de estereotipos de género en el ámbito de administración de la justicia en Argentina, en tanto constructos que limitan el reconocimiento de capacidades y vivencias situadas de mujeres y niñas, perpetuando y consolidando violencias hacia las mismas. Siguiendo a Rebecca Cook, Simone Cusack y Bernard Dickens (2013: 3) entendemos a los estereotipos de género como:

[...] una visión generalizada o preconcebida de los atributos, características o roles que poseen o que debieran poseer los miembros de un grupo en particular, como las mujeres. Sin considerar la personalidad, capacidad o cualidades de un individuo, aquellos percibidos como miembros de estos grupos son considerados como poseedores de características que son típicas del grupo.

A los fines de esta presentación, en un primer momento ahondaremos en los marcos de sentidos desde donde se continúan nutriendo gran parte de los discursos jurídicos en Argentina en torno a temas de género, para en una segunda instancia, analizar tres fallos resueltos por distintas sedes judiciales argentinas: en Buenos Aires (2011), Chubut (2010) y el Chaco (2004). Para este estudio, se revisaron diferentes escritos legales, sentencias, demandas, presentaciones ante sedes internacionales, entre otros, vinculados a los tres casos judiciales objeto de estudio. El análisis de la jurisprudencia hará las veces de ventanas analítica desde donde esperamos aportar a la reflexión respecto de cómo operan en los discursos judiciales las construcciones en torno a la sexualidad, condiciones de pobreza y pertenencia étnica y/o racial de las mujeres en Argentina.

\section{La objetividad de la «letra de la ley»}

El derecho, en tanto discurso de saber, esta inmerso y es producido por una voluntad de poder y verdad que responde a un entramado de condiciones históricas sociales y políticas (Aguilera Portales y González Cruz, 2011). Las abstracciones y universalizaciones con las que se articula el discurso jurídico a menudo invisibilizan cuerpos e historias a través de una construcción hegemónica del «sujeto de derechos». Desde este «universal» los modos en que el discurso legal construye a las/os sujetas/os de derecho operan moldeando subjetividades, inclu- 
yendo a unas/os y excluyendo a quienes no se adaptan a los cánones que el sistema establece (Ruiz, 2009).

Las sentencias judiciales son una de las versiones donde los discursos legales, en tanto discursos «dichos, fundamentales, o creadores» (Foucault, 2002: 26) plasman con enorme contundencia su performatividad (Sabsay, 2011), llevando incluso a convertir a los/as sujetos/as en objetos a tutelar, castigar y/o reprimir.

Tal como plantean algunas posturas vinculadas a la teoría critica del derecho, no hay una distancia radical entre crear y aplicar la ley (Barlett, 1990; Jarami1lo, 2000). Desde esta idea, las construcciones discursivas que realizan las Cortes pueden ser comprendidas como una tarea colectiva, a partir de la cual se cristalizan posiciones y discursos sociales históricamente dados. Esta primera afirmación acerca del rol de los jueces y las juezas rediscute los presupuestos hartamente difundidos en el campo legal de la aplicación de «la letra de la ley», es decir, la noción de que para el poder judicial es posible aplicar las normas jurídicas con prescindencia de los marcos ideológicos, políticos, sociales y culturales que el derecho pretende regular (Kennedy, 2010). Develar la inexistencia de una «letra de ley» en tanto independiente de procesos discursivos constitutivos y constituyentes de relaciones de poder, implica correr el velo de la pretendida abstracción y generalización de la ley y evidenciar en términos de Jacqueline Authier-Revuz (2011: 155): «que ninguna palabra es «neutra» sino que está inevitablemente «cargada», "ocupada», «habitada», atravesada por discursos en los que «vivió su existencia socialmente subtenida».

Sigue siendo poco frecuente hallar en la jurisprudencia análisis que pongan en tensión los marcos históricos y cognitivos en los que fueron sancionadas las leyes y lo disímil de los contextos donde se adjudican. En múltiples ocasiones los tribunales continúa perpetuando la ficción de la aplicación de la «letra de la ley» como aparato político e ideológico desde donde se desconocen las relaciones entre poder, discursos, disciplinas y las experiencias vitales de las personas a las que intentan atender.

En este sentido, nos resultan ilustrativas las ideas de Joan Scott (1992: 54) en su crítica al teórico marxista Raymond Williams, acerca del modo de producción del conocimiento en las ciencias sociales:

Los conceptos de experiencia descritos por Williams excluyen el estudio de los procesos de construcción del sujeto, y evitan examinar las relaciones entre el discurso, la cognición y la realidad, la relevancia de la posición o ubicación de los sujetos para el conocimiento que producen y los efectos de la diferencia en el conocimiento. No se hacen cuestionamientos, por ejemplo, acerca de si tiene importancia para la historia que escriben que los historiadores sean hombres, mujeres, blancos, negros, heterosexuales u homosexuales: en vez de ello, «la autoridad del 'sujeto de conocimiento' (se establece) mediante la eliminación de todo lo concerniente a quien habla». 
Este tipo de giros discursivos por otro lado, operan y se potencian en los discursos judiciales en lo que Foucault llama «función del autor» (Foucault, 2002: 30 ), desde donde se intenta producir una disociación entre un sujeto real del discurso y el sujeto hacedor del discurso judicial.

Las condiciones de posibilidad de los discursos judiciales pugnan por sentar la legalidad o ilegalidad de ciertas prácticas, según los cánones dominantes que los propios discurso instituyen (Savoini, 2001) para luego borrar sus interacciones y presupuestos de poder a través de retóricas universalista y de abstracción. Los discursos en este sentido, suponen producciones contingentes de verdad, modelos de mundos políticamente constituidos que establecen formas de subjetividad, de inteligir la realidad bajo representaciones disciplinarias específicas. Tanto en el sentido de las formas de control y castigo, como de los sistemas de conocimiento hegemónicos, como es el derecho, las disciplinas gestionan discursos que producen nuestras formas de comprender y actuar sobre el mundo (Foucault, 2002).

A la hora de tratar de interpretar los marcos de sentidos ocultos o velados por la dinámica propia del discurso judicial, es central tomar en consideración, como explicita Paula Viturro (2010: 112), los modos en que los/as los funcionarios/as judiciales tienen acceso a la información envuelta en un caso, así como las fuentes que servirán de lente para el análisis de los hechos, muchas veces fragmentadas histórica e ideológicamente

[...] la identidad o coherencia interna del campo semántico del discurso del derecho, es el resultado de un proceso de producción caracterizado por un incesante tráfico de discursos disciplinares de diferente origen, forma y función que si bien fijan y determinan las condiciones de posibilidad de surgimiento material del discurso jurídico, son finalmente eludidos o desconocidos por este.

Es dable pensar así, que los discursos construidos desde las Cortes se encuentran inmersos en marcos de sentido comunes a otros tipos de discursos sociales. Siguiendo aquí a Rosi Braidotti (2000) entendemos al discurso judicial enmarcado en un proceso que comprende una serie de relaciones de poder, donde lo textual y sus efectos se encuentran en estrecha relación con un sistema sociosombólico de ordenación social. Más concretamente, podemos ver que el discurso judicial en temas de género y sexualidad ha tenido como referentes principales ciertos marcos cognitivos fuertemente influenciados por construcciones de raíz religiosa, por razones de configuración de los Estados modernos, así como por discursos biomédicos sustentados en razones de orden biológico (Meloni Vieira, 2008). El establecimiento de estos marcos cognitivos responde a la determinación de un tipo de poder social y cultural específico, desde el cual los argumentos pueden ser compartidos, reapropiados y actualizados a las distintas épocas y circunstancias socioculturales, por una tipología no homogénea de actores que comparte una moral común (Vaggione, 2009). Los discursos jurídicos 
reflejan toda su performatividad en relación a temas de género y sexualidad como uno de los modos de construir naturalizaciones y universalizaciones que perpetúan la violencia y discriminación contra diversas identidades que irrumpen la pretendida hegemonía del 'sujeto de derecho' (Cusack y Timmer, 2011).

Si como lo adelantábamos, el accionar de los movimientos feministas y de mujeres lograron politizar una agenda de género logrando dar luz a las múltiples trayectorias y realidades de sujetas/os históricamente excluidas/os a un ámbito privado y/o negados por ordenes hegemónicos, este proceso ha implicado también fuertes disputas y resistencias en los ámbitos sociopolíticos. Una de las mayores disputas en este campo remite a las discusiones imbricadas en la sexualidad de las mujeres, esto es a las discusiones por el control de la sexualidad y la reproducción de las mujeres en tanto sistema de ordenación social (Foucault, 2002; Meloni Vieira, 2008). Al ingresar a los debates públicos sobre la sexualidad de las mujeres, y otras disidencias sexuales, continúan operando una serie de preceptos morales, políticos, médicos, legales y religiosos que pugnan por preservar el dispositivo de la sexualidad en tanto sistema de ordenación y jerarquización legal que se presenta como natural y ahistórico (Foucault, 2010; Rubin, 1989). Persisten y son harto frecuentes en los discursos judiciales, los relatos sobre las «buenas mujeres» o «mujeres tradicionales» (Escobar y Garcés, 2011), imágenes creadas históricamente por hombres, el esposo, el padre, el cura, el juez, el médico, etc. quienes crearon estos retratos estableciendo los límites y parámetros donde se desglosan una serie de funciones y roles que las «buenas mujeres» deberían desplegar para ser parte de esta categoría o bien ser «el afuera», «las otras», las malas mujeres. Otro de los relatos fuertemente presentes en este sentido es el de la «tradición». El relato de la tradición opera como un constructo que, en términos de Michel Foucault (1991: 33-34), provee: «un estatuto temporal singular a un conjunto de fenómenos a la vez sucesivos e idénticos (o a menos análogos) donde se diluyen las especificidades propias del origen y su devenir».

A partir de este escueto estudio, intentaremos poner en evidencia algunos de los discursos judiciales desde donde se asocia a las mujeres a un «insoslayable destino reproductivo», y/o a «una cosificación de los deseos masculinos».

\section{Las violaciones de la colonia que nunca acaban ${ }^{4}$}

En octubre del año 2003, LNP5 una joven de 15 años de edad perteneciente a una comunidad de pueblos originarios Toba (Qom), fue violada por tres jóvenes

4 Cámara Segunda en lo Criminal. Sentencia 95: «ROJAS HUMBERTO DARIO - ANRIQUEZ LUCAS GONZALO - PALAVECINO LEONARDO JAVIER - Expte. N. 72, foja 963, año 2004, Sec. N. - 3».

5 En virtud de la trascendencia pública que tomaron los procesos judiciales que analizamos en este trabajo decidimos sólo referenciar las iniciales de las mujeres y niñas involucradas en los mismos. 
criollos en la localidad de El Espinillo, situado en la región del Impenetrable provincia del Chaco, noreste argentino. A pesar de las amenazas ejercidas para que LNP no denunciara la violación, la joven fue a la comisaría donde la tuvieron de pie varias horas sin recibir la denuncia policial. Finalmente, la denuncia fue tomada a la madre de LNP, quien hablaba escasamente el español, esto sucedió recién cuando toda la comunidad se manifestó frente al destacamento policial y presionó para que la atendieran. En ningún momento se respetó el derecho constitucional de legítima defensa, jamás se le ofreció la asistencia de un/a traductor/a. LNP fue revisada por un médico del centro de salud quien, sin tomar en cuenta sus heridas, volvió a realizarle tacto en las zonas afectadas por la violencia sexual.

En cuanto al juicio por la violación a LNP, éste desarrolló primero en Castelli, a más de 100 kilómetros del pueblo donde residía la joven y su familia, y luego en Roque Sáenz Peña, a 300 kilómetros de El Espinillo, nuevamente sin traductores del idioma de la lengua original. Luego de varios meses en los que se investigó principalmente a LNP, en agosto del año 2004, los tres imputados fueron absueltos y quedaron en libertad, al no recurrirse el fallo la sentencia quedó sin posibilidad de apelación ante otro tribunal nacional (Della Siega, 2010).

En la sentencia las discriminaciones basadas en razón del género y la etnia fueron innumerables. El juez de la causa, Ricardo Domingo Gutierrez (2004: 2), expresó respecto de los testimonios de los/as testigos que los mismos: «son descabellados, porque la razón de esto (la denuncia) es el recelo y la discriminación propia de esa zona entre criollos y tobas», dejándose así de lado pruebas vitales, como declaraciones de tres testigos, porque eran de condición «tobas».

Asimismo, el juez se hizo eco de la declaración del acusado principal, quien manifestó haber accedido carnalmente a LNP, afirmando que la joven había consentido el acto sexual, ya que se prostituía, que él pagaba habitualmente por sus favores sexuales, los que se realizaban en una gomería de la zona. Estas declaraciones fueron desmentidas durante el juicio por el dueño del local quien confesó que los acusados le ofrecieron dinero para que mintiera. Asimismo, el juez justificó la violencia sexual a través de su naturalización (Gutierrez, 2004: 2-8):

[...] la Fiscalía confunde delito de violación por la violencia sexual que puede estar presente en un acto consentido, por lo cual la violencia es un dato que resulta indiferente». La materialidad del núcleo fáctico de la imputación - acceso carnal por vía anal - es una circunstancia que resulta plena y claramente probada. (...) Las heridas son atribuidas a que en la vía anal no se produce la lubricación natural que tiene la vagina y al ímpetu con que se intenta la penetración, (...) máxime si tenemos en cuenta la juventud del sujeto activo, edad en que la excitación sexual suele ser mucho más impetuosa y más aún ante una ingesta alcohólica - que fue reconocida por el autor y constatada por el médico - que suele producir mayor desenfreno.

Las/os sujetas/os involucradas/os van construyéndose por medio de una serie de atributos que los/as conforman o no, dentro de lo cánones de la hetero- 
normatividad patriarcal. El discurso judicial va constituyendo a los/as sujetos/as frente a la ley y frente a otros/as a través de múltiples interpelaciones. Este discurso opera desde una matriz antagónica colonial. Lo activo, lo vinculado al campo de la fuerza, fue atribuido a los hombres involucrados en el caso, mientras a LNP, se la investigó principalmente para indagar cuan «fuera» estaba de los márgenes de la pasividad, obediencia o de lo doméstico, para así acallar y hasta descartar completamente su palabra y subjetividad. La fuerza de esta matriz antagonista a la vez que perpetúa y administra la violencia colonial, invisibiliza y normaliza a los/as sujetos/as a través de las abstracciones y giros pretendidamente universalistas del discurso jurídico (Haber, 2011) ${ }^{6}$.

\section{La maternidad como mandato ¿inevitable? ${ }^{7}$}

En la ciudad de Comodoro Rivadavia, provincia de Chubut, en 2010 se rechazó la solicitud de autorización de un aborto no punible ${ }^{8}$, realizada por la madre de una joven de 15 años quien había quedado embarazada luego de ser violada por su padrastro. Entre lo expuesto por la jueza, Verónica Daniela Robert, para denegar el derecho que le atendía a la niña, se encuentra el argumento por el cual entendía que la continuación del embarazo no afectaba la salud de la joven, contrariando a las distintas pericias solicitadas en el proceso ${ }^{9}$. La jueza de primera instancia estrechó al máximo la noción de salud, desatendiendo los deseos explicitados, en más de una oportunidad, por la niña de no continuar con el embarazo. Además con su fallo, el tribunal dejó de lado el mandato jurídico por el cual a la niña la asistía un recurso legal, ya que la solicitud se encon-

6 En este caso intervinieron al tomar conocimiento de los hechos, dos organizaciones de mujeres, el Instituto de Género, Derecho y Desarrollo de Rosario y el Comité de América Latina y el Caribe para la Defensa de los Derechos de la Mujer quienes presentaron una denuncia, ante el Comité de Derechos Humanos de Naciones Unidas en el año 2007 denunciando al Estado nacional y a la provincia de Chaco, por la violación de los derechos humanos de LNP. Tanto el gobierno de la provincia del Chaco como el gobierno nacional reconocieron su responsabilidad ante la violación de los derechos de LNP en sede internacional.

7 Juzgado de Familia N ․o 3, Comodoro Rivadavia «FUENTES, Aurora Luisa s/ Medida Autosatisfactiva», Expediente N.․ 17/2.010.

$8 \quad$ El aborto en Argentina se encuentra penalizado, salvo para una serie de presupuestos contemplados en el artículo 86 del Código Penal: «El aborto practicado por un médico diplomado con el consentimiento de la mujer encinta no es punible: (1) Si se ha hecho con el fin de evitar un peligro para la vida o la salud de la madre y si este peligro no puede ser evitado por otros medios; o (2) si el embarazo proviene de una violación o de un atentado al pudor cometido sobre una mujer idiota o demente. En este caso el consentimiento de su representante legal deberá ser requerido para el aborto».

9 Las pericias psicológicas realizadas en más de una ocasión indicaban la voluntad de la niña de interrumpir el embarazo, destacando además que la continuidad del mismo contra su voluntad implicaba grave riesgo para su integridad psicofísica, incluido riesgo de vida. 
traba contemplada en las autorizaciones de aborto previstas en el país ${ }^{10}$. Entre los diversos estereotipos que la jueza arguye en su sentencia se destaca el hecho de culpabilizar a la madre de la niña por lo sucedido. Prescindiendo del contexto social y cultural en los que vivían las mujeres, dejando de lado la evidencia acerca de las condiciones de vulnerabilidad y violencia de distinta índole que vivían tanto la madre como la niña por parte del violador ${ }^{11}$, culpabiliza a la madre de los abusos sufridos por aquella a través de una lectura estereotipada de «familia funcional» (Robert, 2010: 12).

[...] El abuso sexual reiterado, es validado por los informes de psiquiatría y psicología del Hospital Regional a los que ya me referí antes y que dan cuenta de abuso sexual reiterado desde los once años. Estos elementos de juicio me permiten inferir que, de haber obrado la progenitora, desde el momento mismo en que tomó conocimiento, de acuerdo a los deberes que la ley impone a los responsables del ejercicio de la patria potestad, preservando la integridad psico-física de su hija y resguardándola frente al agresor sexual, las lamentables consecuencias que al presente sufre la adolescente, podrían haberse evitado o al menos morigerado. Adviértase que la propia hermana de la víctima, según el informe, da cuenta de un estado de acostumbramiento a una situación de violencia, en la que seguramente en una familia funcional habría generado una reacción defensiva de su propia hermana ante la agresión sexual de su padrastro.

Nociones como la de ver «familia funcional» denotan la pretendida idea de la superioridad moral y legal de la «familia tradicional». Los relatos acerca de la violencia y temor a las que venían siendo sometidas las mujeres, sus condiciones reales de subsistencia, sus voces y relatos, se desdibujan al amparo de discursos que bajo pretensiones de «naturales» se anclan bajo una idea estereotípada de familia funcional. Entre otros giros discursivos, bajo la idea de familia funcional/ /tradicional se invisibiliza en el discurso judicial sistemas de poder y ordenación jerárquica sobre las mujeres. Judith Butler (1990: 48) utiliza la noción de «fábula fundacionista», para referir a estos procesos discursivos de poder, base de siste-

10 Este fallo fue ratificado por la Sala B de la Cámara de Apelaciones de Comodoro Rivadavia. Finalmente el Tribunal Superior de Justicia de la Provincia de Chubut, entendió que el caso encuadraba dentro del supuesto de «aborto no punible» previsto por el inciso $2 .$. , , primera parte del Art. 86 del Código Penal. Vía recurso extraordinario este caso fue resuelto el 13 de marzo de 2012 por la Corte Suprema de la Justicia de la Nación Argentina quien saldó un arduo debate doctrinal y judicial sobre el alcance de las excepciones a la penalización del aborto en Argentina, estableciendo que la permisión del aborto abarca a todos los casos de violación a solicitud de la mujer, mediante la sola presentación de declaración jurada ante médico diplomado.

11 En el fallo se relata diversas circunstancias que denotan las situaciones de extrema vulnerabilidad en las que se encontraban las mujeres. También allí se relata explicitando la violencia de larga data que vivían ambas mujeres de parte del violador quien era Suboficial Mayor de la Policía del Chubut. 
mas jurídicos herederos del liberalismo clásico. La imagen de que determinados comportamientos, prácticas y deseos se remiten a un orden sin historia, que preceden al orden jurídico moderno, hace parte constitutiva de la performatividad social que impone el discurso legal. Así, en el discurso judicial «la naturaleza» logra hacer las veces de retórica legitimante (Haraway, 1999) a través de la cual se logra difuminar y hasta borrar los contextos situados en los que se desarrollan las experiencias vitales de los/as sujetos/as, para ser sustituidos por un discurso normalizador.

\section{Las múltiples caras de la exclusión de las «humanas» ${ }^{12}$}

En marzo de 2011 se publica una nota en el diario Página 12 titulada: «Un abuso que es una cuestión de clase». Allí se relataba un fallo donde se anulaba una condena a un líder religioso por corrupción de menores ejercida en perjuicio de dos niñas de 14 y 16 años de edad ${ }^{13}$.

Los jueces Benjamín Ramón Sal Llargués y Horacio Daniel Biombo (2011) argumentaron que no operaba la calificación legal a los hechos dado que las niñas ya tenían experiencia sexual al momento de ser violentadas, dejando sentado además, que al provenir éstas de familias pobres no se justificaba el agravamiento de las penas ya que, según argumentaron, en estos ámbitos socioeconómicos las relaciones sexuales se ejercen a edades tempranas.

Otro de los puntos que llama la atención en este fallo, refiere a la argumentación realizada en torno a la relativa gravedad de los hechos sufridos por las niñas en relación con otros derechos consagrados constitucionalmente. En el caso concreto, se menciona el derecho a la vida como un absoluto de carácter moral, desconociendo, por un lado, la inexistencia en el ordenamiento jurídico argentino de derechos absolutos, mientras que por otro lado estas afirmaciones implican un claro posicionamiento ideológico y moral del «derecho a la vida», en asociación directa con la protección jurídica de la «personalidad» la que pareciera no ser aplicable a todos/as miembros/as de la comunidad (Piombo, 2011: 5).

[...] y hoy en día, integran la Carta Magna cuatro instrumentos internacionales en materia de Derechos Humanos que colocan en situación de primacía, primero el derecho a la vida, por sobre todos los demás, que quedan en rangos subordinados. Es que constituye la llave para gozar de todos los demás. Incluso, el segundo derecho en rango que aparece cristalizado en dichos Convenios es el ser considerado

Sala Primera del Tribunal de Casación Penal de la Provincia de Buenos Aires AVALOS, Francisco Domingo s/Recurso de Casación. Causa N. 18.560.

13 Este fallo fue apelado ante la Suprema Corte de Justicia de la Provincia de Buenos Aires, quien en diciembre de 2012 declaró su nulidad por considerarlo arbitrario y por estar fundado en prejuicios discriminatorios. 
persona, esto es, un ser con derechos y no una mera cosa o bien disponible por gobernantes y regímenes políticos. «Entonces, cuadra imponer pena en todos los demás delitos teniendo muy presente que las mayores sanciones sólo deben caber cuando las conductas atacan aquellos bienes (vida y personalidad), y no los demás protegidos en el Código Penal [...]

Esta construcción epistémica y normativa de los derechos humanos lejos de toda de neutralidad constituye y perpetúa sistemas de subordinación, construidos e impuestos política y discursivamente como pertenecientes a un orden natural y universal. La retórica de derechos humanos evidenciada en la sentencia, hace imperiosa la necesidad de ahondar en cómo operan determinados marcos cognitivos en torno a las concepciones de derechos humanos en los tribunales argentinos. Esto es, cómo determinados constructos funcionan a modo de lentes epistémicos respectos de poder sentar socialmente como «legítima» una visión respecto de los derechos humanos, contribuyendo, en muchos casos, a perpetuar órdenes de exclusión y violencia hacia determinados/as sujetos/as. El origen histórico donde se asentaron política, cultural y económicamente los derechos humanos, se encuentra fuertemente marcado por una división social, sexual, étnica y territorial, lo que incide en el acceso diferenciado a bienes y recursos necesarios para el ejercicio de una vida digna. Esta mirada crítica en torno a la configuración de los derechos humanos ha llevado a diferentes corrientes a sostener que el origen de los mismos remite a una serie de luchas sociales que se fueron construyendo cultural e históricamente como universalmente legitimas (Gallardo, 2008; Herrera Flores, 2008). En tanto procesos políticos y sociales de lucha por la dignidad, por el logro de revertir jerarquías y exclusiones injustas, es central no descuidar la incidencia de la retórica de los derechos humanos que articulan diversos actores que pugnan por el mantenimiento del estatus quo de órdenes de dominación patriarcal.

\section{Reflexiones Finales}

En este trabajo hemos intentado reflexionar en torno del campo legal y su conexión con la violencia contra mujeres y niñas, prestando especial atención a uno de los actores claves del mismo, las Cortes. A estos fines, hemos abordado cómo los contextos de violencia contra mujeres y niñas son, por lo común, atravesados por una serie conexa de factores individuales y estructurales donde se configuran y perpetúan estas violencias. La abstracción de los condicionantes sociales, ideológicos y/o culturales de los discursos jurídicos es lograda a través de una serie de giros lingüísticos a través de los cuales se busca afirmar valores transubjetivos y de carácter universal, sustentados en un supuesto consenso ético los que en ocasiones invisibilizan o niegan las múltiples diferencias intersubjetivas de las personas a quienes pretende regular. 
Así, más allá de los importantes avances legales de los que se pueden dar cuenta en materia de erradicación de las violencias contra las mujeres, y de las diversas críticas que podamos hacer respecto de las implicancias de transpolar las demandas de los movimientos sociales en lenguajes jurídicos, creemos que a la fecha el campo de lo judicial es aun un espacio de luchas marcado por las tensiones que se dan por los contenidos escritos de las layes, como por la posterior lectura que de éstas hagan los tribunales.

Nuestra intención aquí ha sido intentar ponernos en dialogo con quienes ven en el campo de lo legal, una de las arenas propicias para lograr la resolución de distintos tipos de desigualdades y violencias contra las mujeres. Evidenciar los casos donde es el propio sistema de justicia quien consagra y consolida profundas injusticias y múltiples formas de violencia nos lleva a reflexionar críticamente respecto del creciente rol de los poderes judiciales en las democracias contemporáneas y su aun fuerte atravesamiento por una cultura heteropatriarcal, condicionada además por preconceptos de clase, etnia, raza, entre otros.

Consideramos necesarios interrogarnos, una vez más, respecto de que no/discursos y no/actores se consideran o invisibilizan en los espacios sociopolíticos y cómo estas decisiones epistémico/políticas se normalizan en el discurso legal/judicial.

\section{Referencias}

Aguilera Portales, Rafael Enrique; González Cruz, Joaquín (2011), «Derecho, Verdad y Poder en la teoría político jurídica de Michel Foucault», A Parte Rei, 74, pp. 2-12.

Authier Revuz, Jacqueline (2011), Detenerse ante las palabras. Estudios sobre la enunciación, Montevideo, Universidad de la República.

Barlett, Catherine (1990), «Feminist Legal Methods», Harvard Law Revie, 103, 4, pp. 829-888.

Braidotti, Rosi (2000), Sujetos Nómades. Barcelona, Paidós.

Butler, Judith (1990), El género en disputa: El feminismo y la subversión de la identidad, México D. F., Paidos.

Chiarotti, Susana (2006), «Utilizar la ley como herramienta de cambio. El CLADEM, Red Regional de Feministas que Trabajan con el Derecho», in Nathalie Lebon and Elizabeth Maier (coords) De lo privado a lo público. 30 años de lucha ciudadana de las mujeres en América Latina, México, Siglo XXI/UNIFEM/LASA, 2006, pp. 380-390.

Chinkin, Christine (2012), «Acceso a la justicia, género y derechos humanos» in Defensoría General de la Nación, Violencia de Género: Estrategias de litigio para la defensa de los derechos de las mujeres, Buenos Aires, Defensoría General de la Nación, pp. 15-49.

Cook, Rebecca; Dickens, Bernard; Cusak, Simone (2013), «La estereotipación poco ética de la mujer en la salud reproductiva», in Alejandro Madrazo, Estefanía Vela y Cecilia Garibi (org.) Discusiones sobre Género, Sexualidad y Derecho: Taller 2010, México D.F, Fontemara, pp. 123-134.

Della Siega, Viviana (2010), Caso LNP. Discriminación por Género en el Sistema de Justicia en casos de Violencia Sexual, Rosario, Acquatin.

Escobar García, Bibiana; Garcés Gómez, Juan Felipe (2011), «Mujeres tradicionales, mujeres modernas: Apuntes iniciales desde la conquista al voto», in Bibiana Escobar García, Género y Derecho, Medellín, Ediciones Unaula, 4, pp. 7-69. 
Foucault, Michel (1991), La arqueología del saber, México D.F, Siglo XXI Editores.

Foucault, Michel (2010), Historia de la Sexualidad 1. La voluntad del saber, México D.F, Siglo XXI Editores.

Foucault, Michel (2002), El orden del discurso, Barcelona, Tusquets Editores.

Gallardo, Helio (2008), «Sobre las Generaciones de Derechos Humanos», [on líne] Disponible en: < http: //heliogallardo-americalatina.info/index.php?option=com_content\&task=view\&id=102\&Itemid=9>. [Fecha de Consulta: 17 de Octubre de 2012].

Haber, Alejandro (2011), «Nometodología Payanesa: Notas de Metodología Indisciplinada», Revista de Antropología, 23, 1er Semestre, pp. 9-49.

Haraway, Donna (1999), «Las promesas de los monstruos: Una política regeneradora para otros inapropiados/bles», Política y Sociedad, 30, pp. 121-163.

Herrera Flores, Joaquín (2008), La reinvención de los derechos humanos, Sevilla, Ensayando, Atrapasueños.

Jaramillo Sierra, Isabel (2000) «La crítica feminista al derecho», in Robin West and Isabel Jaramillo, Género y teoría del derecho, Bogota, Siglo del Hombre Editores, Instituto Pensar y Facultad de Derecho de la Universidad de los Andes, pp. 25-60.

Kennedy, Duncan (2010), Izquierda y Derecho. Ensayo de teoría jurídica crítica, Buenos Aires, Sigloveitiuno editores.

Meloni Vieira, Elizabeth (2008), A Medicalização do Corpo femenino, Rio de Janiero, FIOCRUZ.

Mones, Belkys y Guzmán José (1998) «Pobreza e inequidad de género: salud y derechos sexuales y reproductivos en América Latina y el Caribe», Agenda Salud, 10, pp. 1-8.

Carbajal, Mariana (2011), «Un abuso que es una cuestión de clase» Página 12, [on line] Disponible en: <http: //www.pagina12.com.ar/diario/sociedad/3-165257-2011-0331.html > [Fecha de Consulta: 14 de Noviembre de 2012]

Pecheny, Mario; De La Dehesa, Rafael (2009), «Sexualidades y políticas en América Latina: un esbozo para la discusión», ponencia presentada en Diálogo Latinoamericano sobre Sexualidad y Geopolítica, Río de Janeiro, 24 de agosto.

Rodríguez, Matilde (2008), «Análisis de la cultura jurídica en la administración de la justicia", in Patricia Britos (comp.) Actas de las primeras jornadas de filosofía política: democracia, tolerancia, libertad, Bahía Blanca, Universidad Nacional del Sur, Ediuns.

Rubin, Gayle (1989), «Reflexionando Sobre el Sexo: Notas para una Teoría Radical de la Sexualidad», in Carol Vance (org). Placer y Peligro: Explorando la Sexualidad Femenina. Madrid, Revolución, pp. 113-190.

Ruiz, Alicia (2009), «Quien dice qué es el bien común», in Emilio, Ruchansky, Políticas de Reconocimiento II, Buenos Aires, Ají de Pollo, pp. 118-137.

Sabsay, Leticia (2011), Fronteras Sexuales. Espacio urbano, cuerpos y ciudadanía, Buenos Aires, Paidós.

Savoini, Sandra (2001), «La mujer en el discurso de la Iglesia sobre la ley de salud reproductiva y sexualidad», in María Teresa Dalmaso, (comp.) Figuras de Mujer. Género y Discurso Social, Córdoba, Ferreyra editor.

Scott, Joan (1992), «Experiencia», in Judith Butler and Joan Scott, Feminists Theorize the Political, Londres, Grupo Taylor \& Francis, pp. 42-73.

Vaggione, Juan Marco (2009), «La sexualidad en el mundo post-secular», in Mario Gerlero (comp.), Derecho a la sexualidad, Buenos Aire, David Grinberg Libros Jurídicos, pp. 141-159.

Viturro, Paula (2010), «Reflexiones acerca del litigio en materia de géneros y sexualidades», in Equipo Latinoamericano de Justicia y Género (ELA) Derechos de las Mujeres y discursos Jurídico, Buenos Aires, ELA, pp. 113-131. 


\section{Documentos consultados:}

AVALOS, Francisco Domingo s/ Recurso de Casación. Sala Primera del Tribunal de Casación Penal de la Provincia de Buenos Aires.

Caso LNP contra el Estado Argentino. Comunicación No. 1610/2007 en trámite ante el Comité de DDHH de Naciones Unidas.

«ROJAS HUMBERTO DARIO - ANRIQUEZ LUCAS GONZALO - PALAVECINO LEONARDO JAVIER - Expte. N.o 72, fo. 963, año 2004, Sec. N.. 3», Cámara Segunda en lo Criminal. Sentencia 95:

F. A. L. s/ MEDIDA AUTOSATISFACTIVA», Expte. N. 17/2.010, Juzgado de Familia N.ㅇ 3, de la ciudad de Comodoro Rivadavia.

María Angélica Peñas Defago. Abogada por la Universidad Nacional de Córdoba, Argentina (UNC). Diploma en Ciencias Sociales con especialización en Género y Políticas Públicas por FLACSO-Argentina.

Becaria doctoral del Consejo Nacional de Investigaciones Científicas y Técnicas por el Centro de Investigaciones Jurídicas y Sociales, UNC.

Nevado 2821 PB. Barrio Parque Capital Sur. Córdoba Capital-Argentina. CP: 5016 angelicapdefago@hotmail.com

Artigo recebido em 30 de setembro de 2014 e aceite para publicação em 30 de dezembro de 2014. 